\title{
MODERN DESIGN AND CONTROL OF AUTOMATIC TRANSMISSION AND THE PROSPECTS OF DEVELOPMENT
}

\author{
Dejan Matijević \\ The School of Electrical and Computer Engineering of Applied Studies, Belgrade, Serbia \\ Ivan Ivanković* \\ University of Belgrade, Faculty of Mechanical Engineering, Belgrade, Serbia \\ Dr Vladimir Popović \\ University of Belgrade, Faculty of Mechanical Engineering, Belgrade, Serbia
}

The paper provides an overview of modern technical solutions of automatic transmissions in automotive industry with their influence on sustainable development. The objective of the first section is a structural view of specific constructions and control systems of presently used automatic transmissions, with emphasis on mechatronics implementation. The second section is based on perspectives of development, by integrating some branches of soft computing, such as fuzzy logic and artificial neural networks in order to create an optimal control algorithm for obtaining a contribution to fuel economy, exhaust emission, comfort and vehicle performance.

Key words: Automatic transmission, Mechatronics, Automotive industry, Soft Computing

\section{INTRODUCTION}

Almost all automobiles in use today are driven by internal combustion engines, which are characterized by many advantages, such as relatively good efficiency, relatively compact energy storage and high power - to - weight ratio [07].

But, fundamental disadvantages are:

- Incapability to produce torque from rest (zero engine speed) and relatively low torque at small engine rpm ;

- an internal combustion engine only produces maximum power at a certain engine speed;

- fuel consumption is strongly dependent on the operating point in the engine's performance map;

It is not hard to conclude that speed characteristic of internal combustion engine is not the most appropriate for the vehicle movement with a high efficiency. The desired characteristic is "ideal traction hyperbola" which can be obtained only by maximum available engine power $P_{\text {max }}$ through all vehicle speeds [07].

The area below the ideal traction hyperbola in the traction diagram, shown on Figure 1 for vehicle with a four speed gearbox, could be used for vehicle movement. Upper limitation is related to maximum traction force between tires and road, which is depended by coefficient of friction and normal load on the drive axle. Lower limitation is defined by maximal speed that vehicle can reach. Shaded areas between traction forces through gears are power losses. To decrease power losses and to be as closely as possible to the ideal traction hyperbola, the gearbox with enough gear ratios is needed.

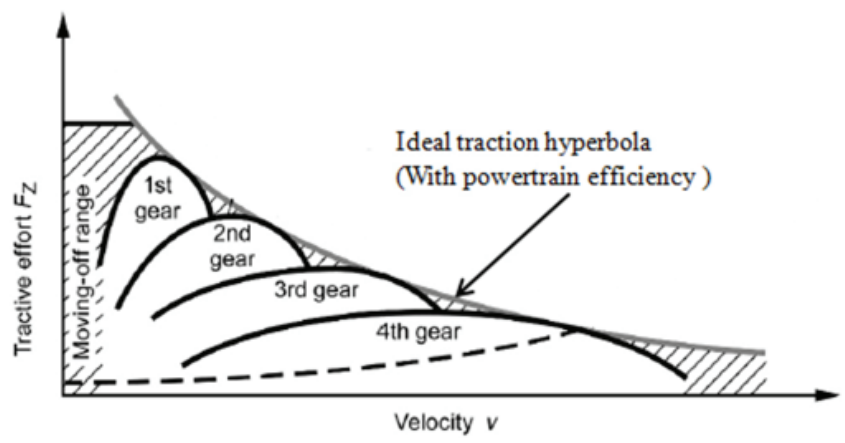

Figure 1: Traction diagram for a vehicle with for four speed gearbox [06]

Besides characteristics of drivability, which should be satisfied by certain type of transmission for specified vehicle, there are also requirements related to the fuel consumption, installation space, comfort, convenience and product costs. It is not easy to fulfill all these demands, but because of high competition, great efforts have been made in the field of research and development. 
It was reflected on automatic transmissions too, because from the beginning of series vehicle production, it has been tended to processes automatization. Gear changing automatization has crucial impact on traffic safety, because driver gets much less tired than with manual transmission, where is demanded constant changing of gear ratio according to the road conditions and traffic situations. This is especially important for city driving.

Despite higher complexity, there are less negative effects on gearbox sustainability and reliability caused by driver's unprofessional handling with automatic over manual transmission.

Utilization of planetary gear sets enabled much greater number of gear ratios than it is possible to obtain with manual transmission (for commercial vehicles up to 18). Continuously variable transmissions have theoretically an infinite number of gear ratios, what leads to maximal approximation of ideal traction hyperbola.
But even today, when benefits of control systems and mechatronics utilization are clearly evident, many people especially in Europe (where percent of sold passenger cars with AT is only 15 to 20 percent, while in North America and Japan this percentage goes up to 80 to 90 [02]) believe that automatic transmission are too much expensive for maintenance and that are less reliable because of their complexity and connections with other electronic systems in the vehicle, without deep understanding of their advantages. But, automatic transmission utilization differs through vehicle segments, and it is shown on Figure 2. Of course, the highest percentage of their application is in Luxury segment. Small and Mini segments are economically unsuitable for installation of automatic transmissions. It is important to notice a positive grade in automatic transmission usage in Sports segment in the last few years and the reasons for that are decreasing of gear shifting time (especially with DCT transmissions) and better utilization of engine performance.

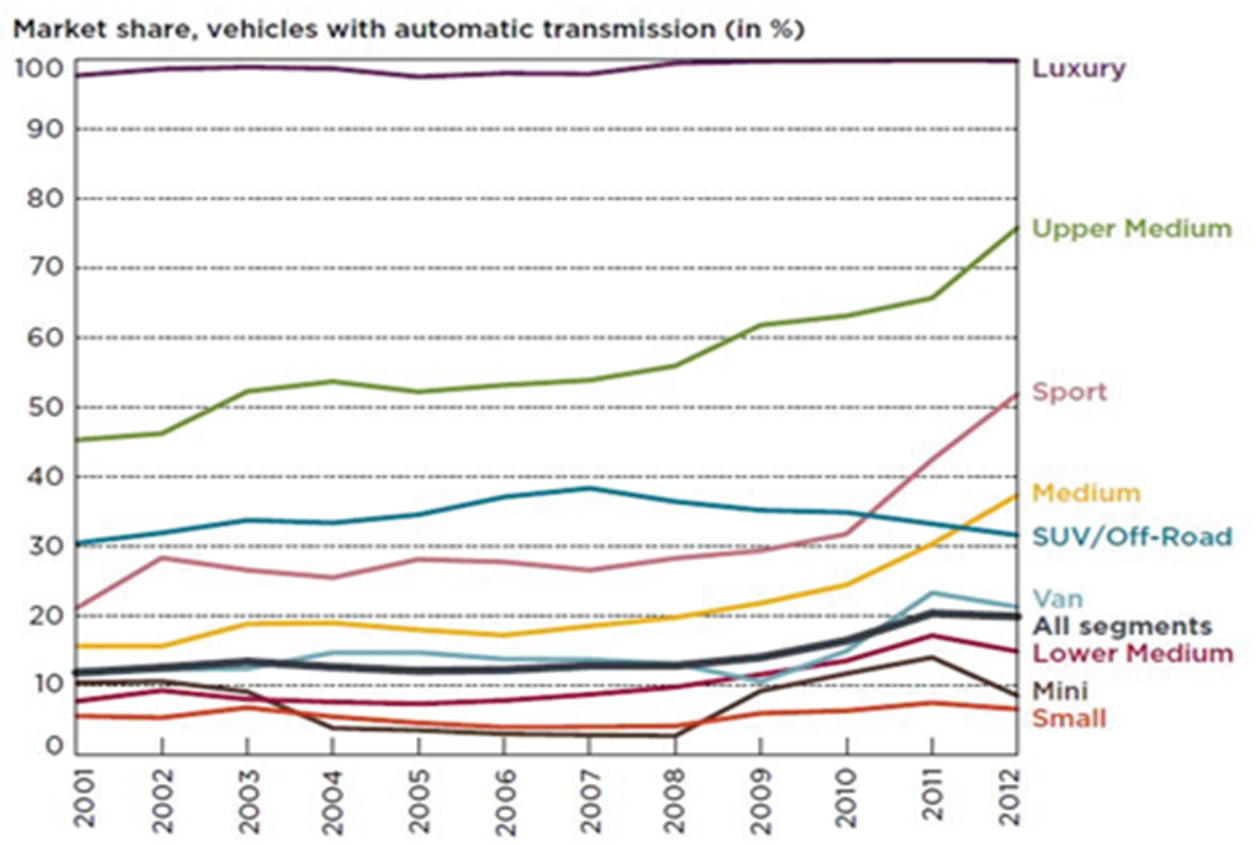

Figure 2: Market share of vehicles with automatic transmissions (in \%) through years

\section{ELECTRONIC TRANSMISSION CONTROL}

Electronic control of automatic transmissions represents an integration of electrics, electronics and hydraulics. The basic functions are achieved by use of sensors, actuators and appropriate software in the transmission control unit (TCU). Advanced functions include networking of the control units into one global system, what enables information exchange between them, by
CAN communication as it is shown on Figure 3. It leads to reduction of costs and complexity while increasing diagnostic functions and reliability. Basic automatic transmission control systems are:

- Automated manual transmission (AMT);

- Hydrodynamic mechanical transmission (HMT);

- Continuously variable transmission (CVT);

- Dual clutch transmission (DCT); 


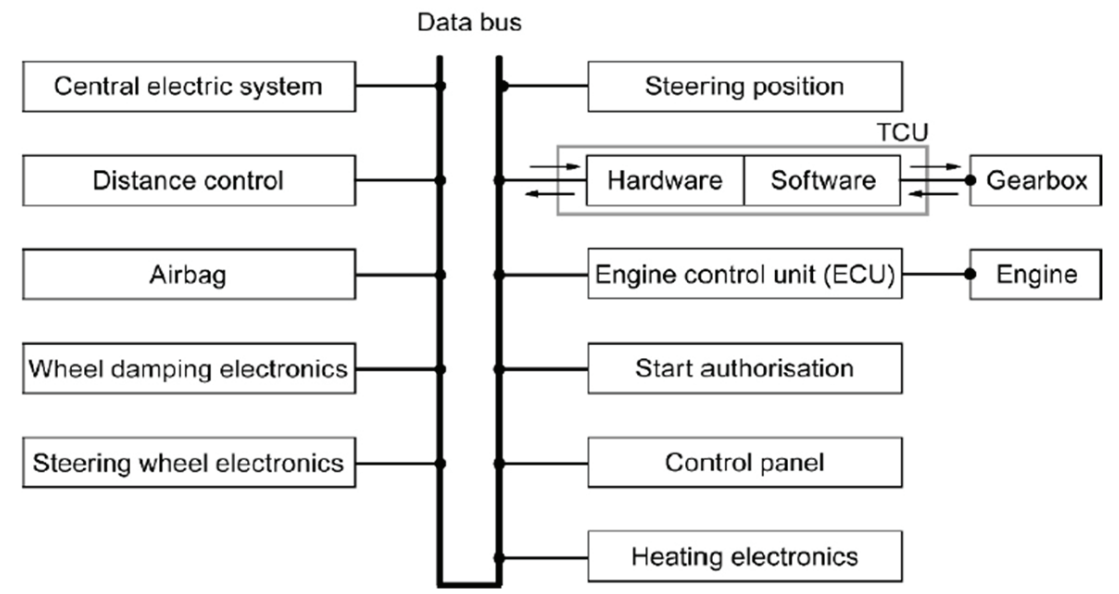

Figure 3: Communication between electronic control units by CAN protocol [06]

\section{AUTOMATED MANUAL TRANSMISSION (AMT)}

The automated manual transmission combines the advantages of manual transmissions with function of automatic transmission [01]. The greatest advantage of this transmission is high efficiency which is characterized for manual transmissions. Their automatization leads to lower specific fuel consumption over manual transmission controlled by average driver. It enables lower level of $\mathrm{CO} 2$ emission, which is one of the most important global issues. Also, by avoiding an installation of the clutch pedal, the increasing safety with operating comfort and convenience are achieved.

Two basic types of this kind of transmission are:

- Electric-motor clutch management (ECM);

- Automated shift transmission (AST);

The basic difference between these two types of transmissions is higher level of automatization of the AST because there is no mechanical connection between the selector lever and the transmission, as it is shown on the Figure 4. Examples of application ECM systems are: Mercedes A - Class, Fiat Seicento and Hyundai Atoz. Examples of application AST systems are: VW Lupo, MCC Smart and Opel Corsa Easytronic [01]. In conventional systems of manual transmissions, the maximal clutch torque must be $50 \%$ to $150 \%$ higher than defined maximal engine torque. The reasons for that are strong fluctuations of the torque on the flywheel, especially with modern diesel engines, and the requirement that the clutch must transfer engine torque under all extreme conditions. To decrease these negative effects, function of torque correction during gear shifting is implemented in the control system of AST. This method not only that achieves smoother control of the process, but it also enables faster gear shifting. It is achieved because the clutch torque is only marginally above the engine torque. The regulation process enables dropping the clutch torque at the moment when the driver takes his foot off the accelerator pedal, Figure 5.

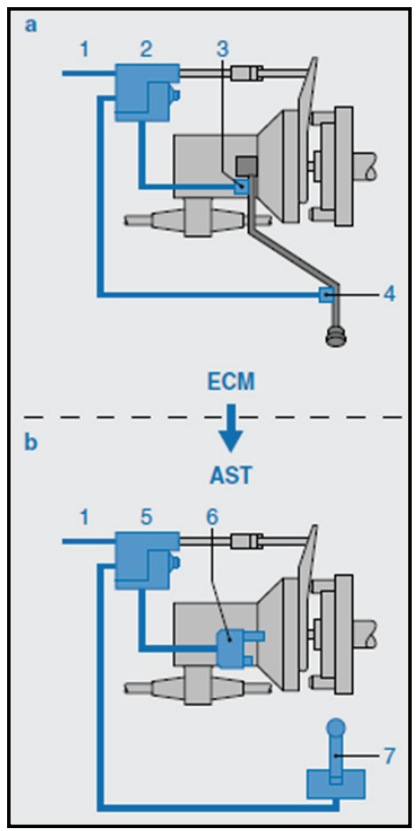

a. ECM

b. AST

1. Available signals

2. Clutch actuator with integrated ECM ECU

3. Gear recognition

4. Shift-intention recognition on shift lever

5. Clutch actuator with integrated AST ECU

6. Transmission actuator

7. Selector lever

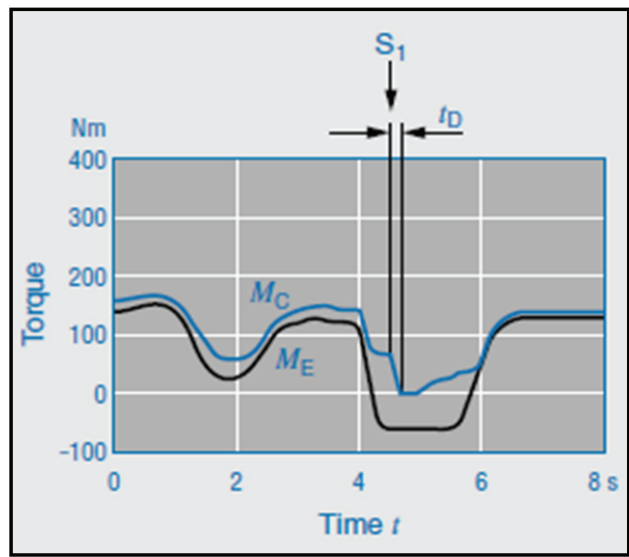

Figure 5: Review of clutch and engine torque control during gear shifting 


\section{HYDRODYNAMIC MECHANICAL TRANSMISSION (HMT)}

The main component of hydrodynamic mechanical transmission is a torque converter. The torque converter is a power take-up element, which works as an additional gear in the start-up range and also serves to damp vibrations [01]. Torque converter is connected to the crankshaft of the engine by flex drive plate. The flex drive plate also has a function to decrease torsion rigidity of the transmission and with massive torque converter, filled with automatic transmission fluid, there is no need for heavy and expensive dual mass flywheel to smooth stresses and vibrations coming from the engine. Function of multiplying engine torque is achieved by stator assembly, located between the pump and the turbine assembly in the torque converter. Characteristic of the torque converter is shown on the Figure 6.

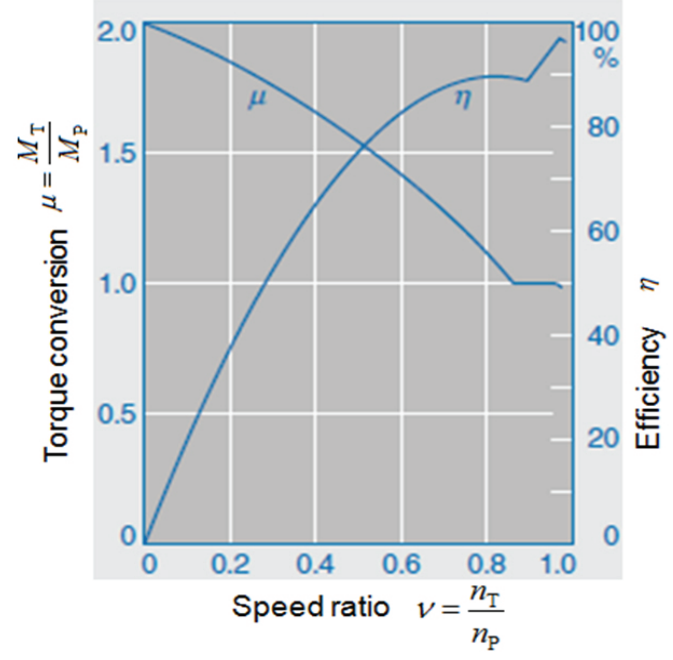

Figure 6: Characteristic of the torque converter [01]

It can be noticed from the diagram on the Figure 6 , that there is a converter area $v<85 \%$ with maximum efficiency up to $90 \%$, and the clutch area $v>85 \%$ when a one-way clutch is activated in order to obtain mechanical connection between pump and turbine assembly. This leads to increased efficiency up to $97 \%$, because fluid slip is eliminated, but there is no torque conversion. In order to accomplish enough gear ratios, for this type of transmission in luxury vehicles usually seven or eight speeds are available, planetary gear sets are used. Different gear ratios are achieved by coupling certain elements of planetary gear sets by bands and clutches. They are regulated by electro hydraulic actuators, controlled by electronic transmission control unit.
The most important basic functions of Hydrodynamic mechanical transmission control are the shift point control, the lockup converter clutch control and engine torque control during shifting [02]. The basic shift point control, which is related also for other transmission control types, uses shift maps which are stored in the unit memory. The shift point limitations are defined by minimal and maximal engine speed. To avoid frequent shifting between two gears under certain engine load and vehicle speed, the hysteresis between the upshift and the downshift characteristic is embedded. To improve this basic function and to obtain higher hysteresis between upshift and downshift characteristics, an adaptive function is incorporated. It can be achieved only by software changes with use of already existing components in the system. The simplest transmission control takes into account just three parameters. These are vehicle speed (determined by the transmission output speed), the throttle position as indicator of engine load and the accelerator pedal position as driver command. The adaptive function uses vehicle acceleration, as additional parameter, which is calculated from transmission output speed over time. Calculated or actual vehicle acceleration is compared with set value which is determined from traction resistance characteristic and depends from actual vehicle speed and engine load. Basic principle of adaptive shift point control is shown of Figure 7.

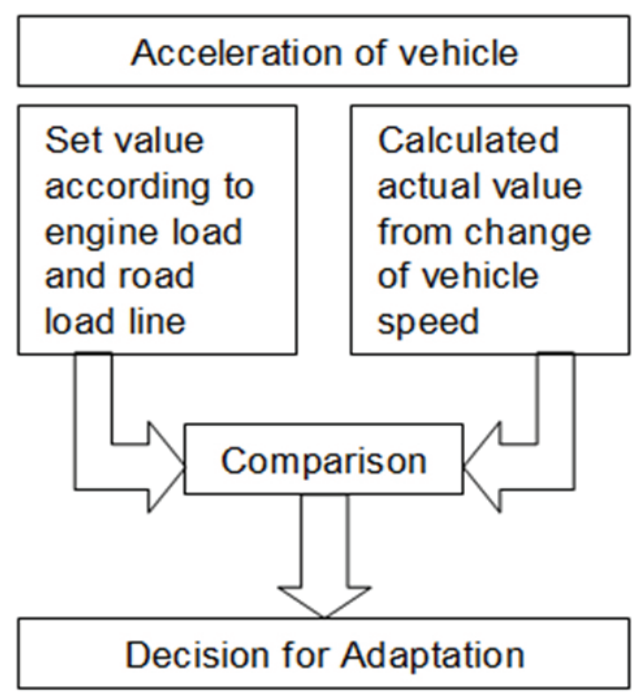

Figure 7: Basic principle of adaptive shift point control [07]

By this way, the shift point correction is obtained what leads to better control of the process and possibility for implementation of different shift maps into the database of the transmission con- 
trol unit (TCU). For example, one shift map can be adopted for low fuel consumption, which has shift points in the range of best efficiency of the engine, and the other one should enable highest engine output power. The selection of appropriate shift map can be done by the driver, with a selector push button or a switch.

Function of lockup torque converter clutch is important for reducing power losses caused by converter slip. For increasing the efficiency it is necessary to close the clutch as often as possible. But beside function of increasing torque, the torque converter is an important component to prevent vibrations coming from the engine. It can be concluded that the clutch activation is a compromise between low fuel consumption and driving comfort. Situations in which the clutch is certainly open are, driving in the first gear, during shifting process and under high torque demand with low engine speeds. Reasons for it are obtaining torque increase for improved acceleration and reduction the level of vibrations under non stationary conditions. In other driving situations which are mainly defined by constant load, the clutch should be closed. Torque converter clutch is controlled by on/off solenoid, pressure regulator or a PWM solenoid.

Like with automated manual transmission, a function of engine torque control during shifting must be incorporated to the process regulation. For obtaining that function, a communication with engine management system is crucial. Depending of engine type and system of mixture formation different methods of engine torque control are possible. For gasoline engines the fastest regulation process is achieved with an ignition angle. It is also used for idle speed regulation. The advantage over throttle valve position regulation, which is characterized by its inertia and need for parallel correction of injection time for obtaining defined lambda factor of the mixture, is shorter response time of the system. Injection quantity correction is applied for diesel engines and beside variation of injection time it also includes injection pressure correction (Common Rail - CR, Unit Pump System-UPS, Unit Injector System - UIS). The parameters of engine torque regulation are defined by calibration data for each combination of the engine, gearbox and the vehicle, so regulation process is controlled by transmission input speed in order to obtain synchronization during gear shifting process.
Generally, during downshift process a short interruption of the tractive power transfer should occur to minimize undesired vibrations incurred by higher revolving energy. During upshift process a torque reduction should be obtained in order to decrease power losses.

\section{CONTINUOUSLY VARIABLE TRANSMISSION (CVT)}

Principle of operation of continuously variable transmission is based on infinite number of gear ratios and because of that its theoretical efficiency is higher than other transmission systems. Because transfer and transformation of power parameters are accomplished by friction element, which is crucial for CVT operation, due to slipping, power losses are higher as higher power transfer is requested.

The largest number of CVT units is made with a belt as wrap element. Figure 8 shows the structure of the most common pulley based CVT systems. If two cones of the pulley fall apart, the diameter of the pulley becomes small; while they are close, the diameter of the pulley is large. Because the length of the driving belt is fixed, when the diameter of the drive pulley becomes small, the diameter of the driven pulley must become large by closing two cones of the pulley together, and vice versa [13].

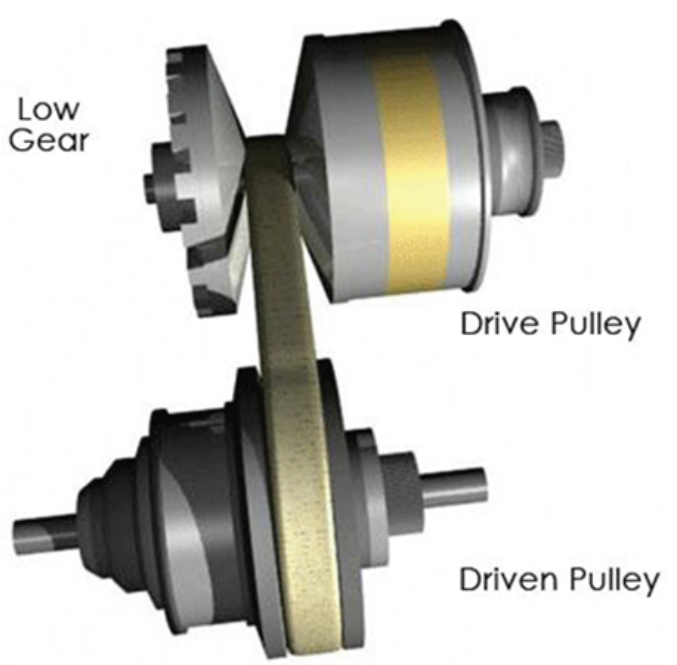

Figure 8: Pulley based CVT [04]

Rubber belts have tendency for straining and slipping, what is the reason for reducing its efficiency. Entering of new materials makes CVT transmission more efficient and reliable. One of design improvements is metal belt, which comprises two steel strips connected with thin highly resistant metal. Metal belts are not slipping and 
with them CVT transmission can transfer higher loads. Also they produce less noise than rubber belt. For greater demands, steel chain could be used as wrap element. It is also flexible, but much more strength than any other element. System with steel chain is implemented with sensor of torque for ensuring enough tension with optimal contact pressure. Depending of the chosen friction elements there are different types of variator's principles which could be in use. Example of mechatronic unit for CVT transmission with both controlled pulleys and the torque converter is shown on Figure 9, and its operating principle on Figure 10.

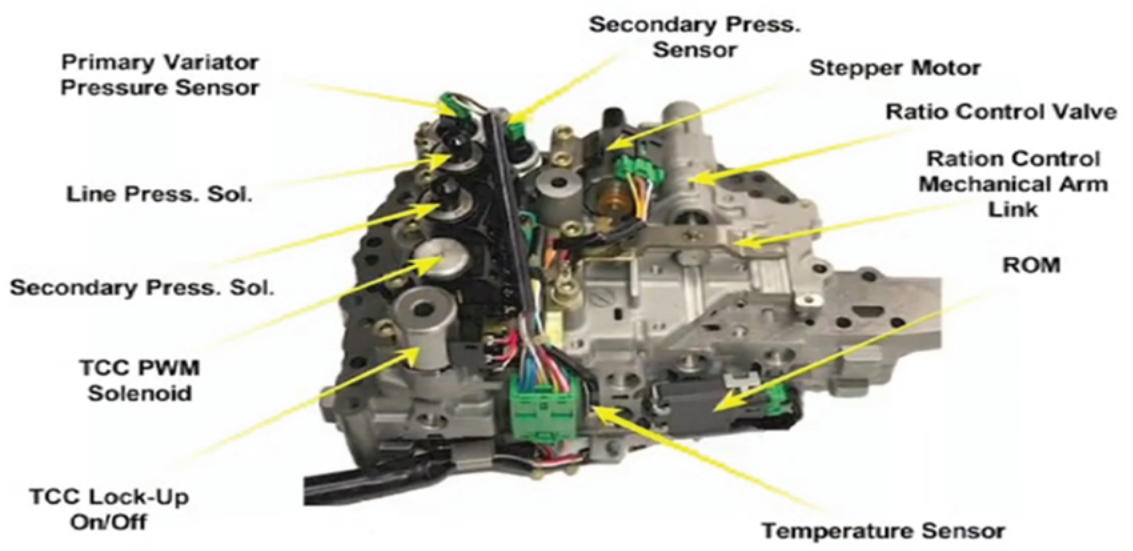

Figure 9: Mechatronic unit for CVT Transmission [06]

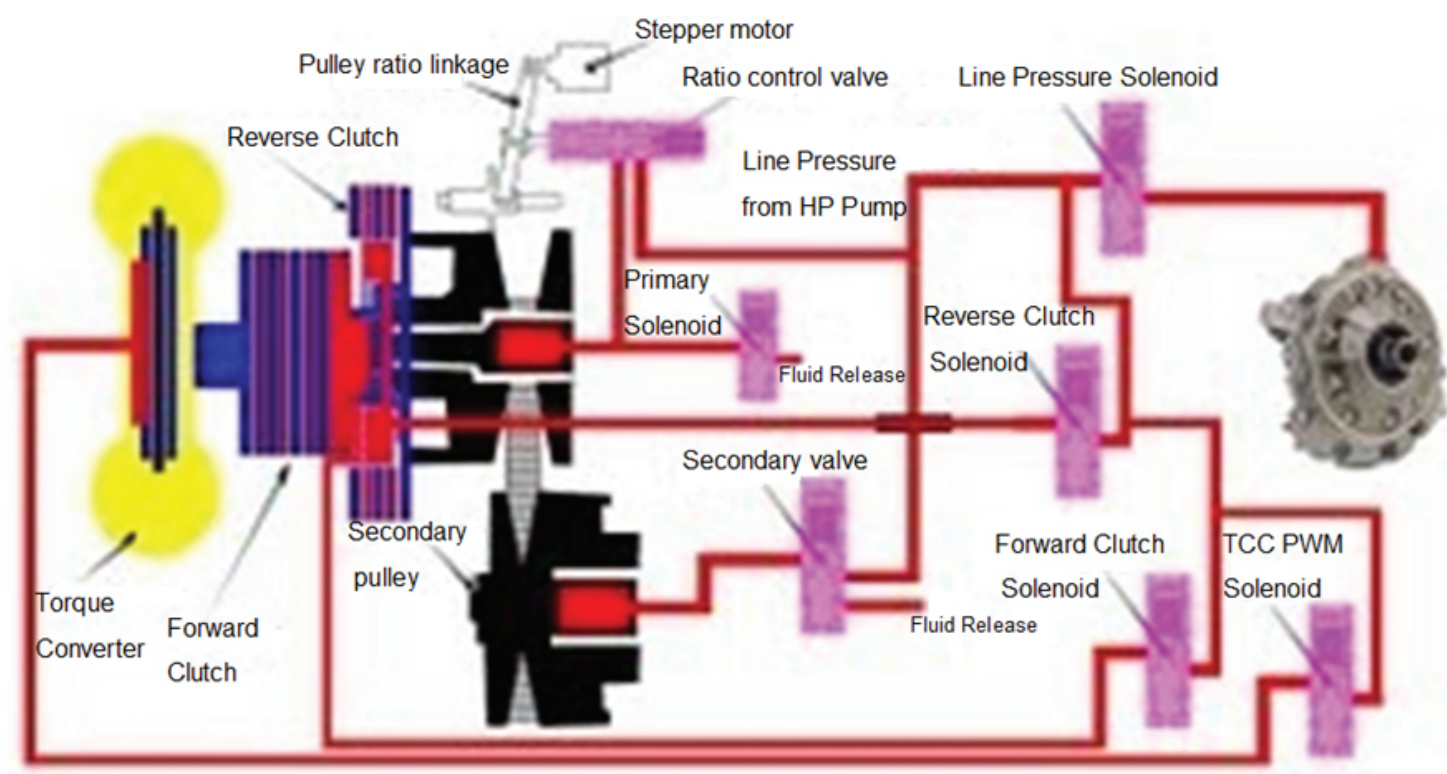

Figure 10: Scheme of control CVT Transmission [06]

The main component of this mechatronic unit is line pressure solenoid valve, which regulates the pressure from a pump in a range 5 - 60 bar. At idle the pressure is 15 bars. Reason for such high pressures is demand for high transmission efficiency, which could be achieved only by strong clamping force of the belt, to decrease belt slippage as much as possible. For achieving sufficient clamping force on the belt, secondary pressure solenoid is responsible. Also, there is a solenoid for the primary pulley, but before the pressurized fluid comes into that solenoid, it must pass through ratio control valve, which is via pulley ratio linkage controlled by stepper motor. For this mechatronic circuit, stepper motor is the least reliable part of the system. But stepper motor enables more precise control, because its proper activation is a condition for gear ratio changing. All CVT units have a planetary gear set for reverse operation and two clutch packs for forward and reverse motion. If there is a torque converter, there are solenoids for lock up clutch regulation. Because torque converter offers good starting response, pulleys transmission ratios could be beneficial to over drive range so large ratio span could be covered. In order 
to achieve better efficiency TCC PWM Solenoid regulates the pressure of the fluid in a range 0 - 10 bars, and there is a TCC Lock-Up On/Off regulator for activating torque converter clutch lock up as soon as possible.

\section{DUAL CLUTCH TRANSMISSION (DCT)}

Dual clutch transmission (DCT) presents the further development of the automated shift transmission (AST), designed and developed by Audi and Volkswagen, with first application in 1992 in motor racing car. This type of transmission has a high efficiency because power transfer is achieved by clutches instead of fluid coupling. Construction of DCT is similar as manual transmission, with application of collar, synchronizer and gear set in order to perform gear shift. Biggest advantage of DCT is fast gear shifting, without interruption of the tractive force, what enables relatively low fuel consumption. [01,13] Dual clutch transmission is characterized by two main shafts and associated clutches in its structure, one for odd (1st, 3rd,5th) and the other for even gears $\left(2^{\text {nd }}, 4^{\text {th }}, 6^{\text {th }}\right)$, as it is shown on Figure 11.

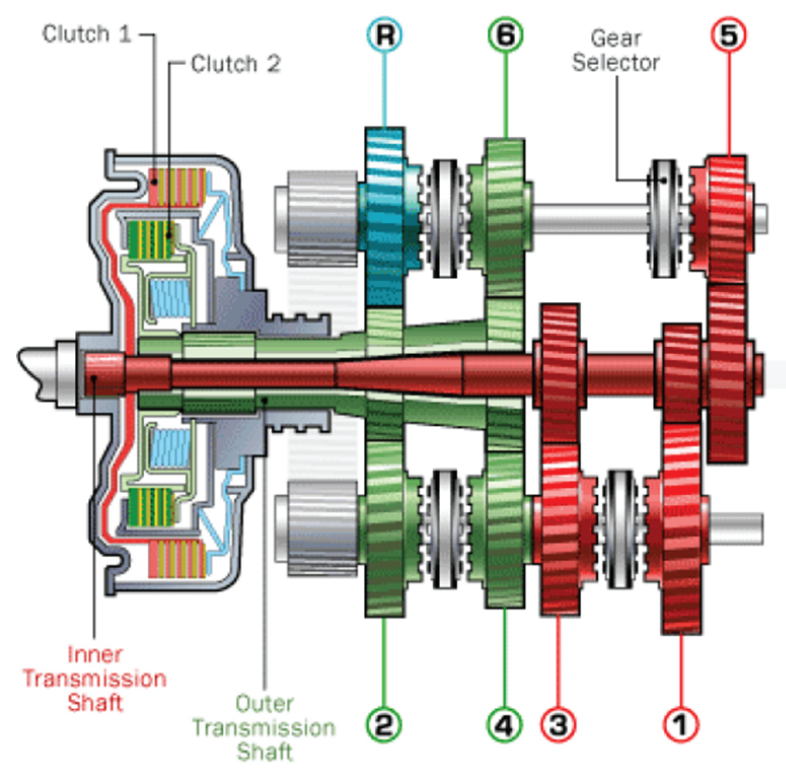

Figure 11: Basic construction of dual shift transmission [13]

As soon as computer detects that the spinning speed of the input shaft is too high, for example in the first gear, it prepares the next speed, by engaging $2^{\text {nd }}$ gear's collar to the $2^{\text {nd }}$ gear. Only after that, the clutch for the odd gears should disengage, and the $2^{\text {nd }}$ gear's input shaft should engage. For smoother application, despite short gear shifting time, it is possible to perform "double clutching" what could be obtained by shift- ing to neutral first in order to adjust the spinning speed of the input shaft, and just after to shift to the next gear. The mechatronics of DCT are housed in the gearbox, surrounded by oil. They comprise an electronic control unit and an electro-hydraulic control unit. The mechatronics form the central control unit in the gearbox. All sensor signals and all signals from other control units come together at this point and all actions are initiated and monitored from here. By hydraulic means, it controls and regulates gear actuators via pressure modulation valves and selector valves, but it also controls the pressure and flow of cooling oil for both clutches. The Mechatronics assembly can adapt to learn the positions of the clutches, the positions of the gear actuators for each specific gear and the main transmission fluid pressure. Example of electro-hydraulic control unit is shown on Figure 12 [11].

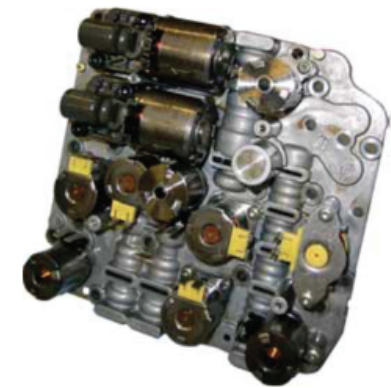

Figure 12: Electro-hydraulic control unit for DCT [11]

\section{DEVELOPMENT OF THE TRANSMISSION CONTROL ALGORITHMS}

In 2013. Rolls - Royce engineers designed Satellite Aided Transmission, new control system where the transmission control unit is connected to Global Position System (GPS) receiver [09]. With this kind of communication, vehicle control system can determinate road profile in front of the vehicle, so gear shift prediction could be achieved. Therefore vehicle performance and fuel economy could be improved, with higher comfort, because problems of inadequate gear shifting on a slope or in a curve could be avoided. But entering navigation systems has even more sense for complex control systems of automatic transmission, which include adaptive functions of self learning. One of the crucial steps in developing of software is calibration process. Because transmission control is nearly connected to the engine management and many other systems, fulfilment of many opposite requirements which should be meet in the best manner for every system in every driving situation, is practically impossible to 
describe with defined mathematical model. Modern software development processes demand very little human interference, or even their complete absence in calibration process. Therefore, fuzzy logic as a branch of logic that uses the degree of participation of some element in the system, more than just strictly true or false definition of its membership, will be very used in modern control systems. Introduction of fuzzy logic is further encouraged by increasing the number of variables which should be calibrated. With fuzzy logic as basis, artificial neural network could be designed. The main advantage of this approach is online training using real-time vehicle data and adaptive calibration on control capability. [08] The block diagram of described algorithm is shown on the Figure 13.

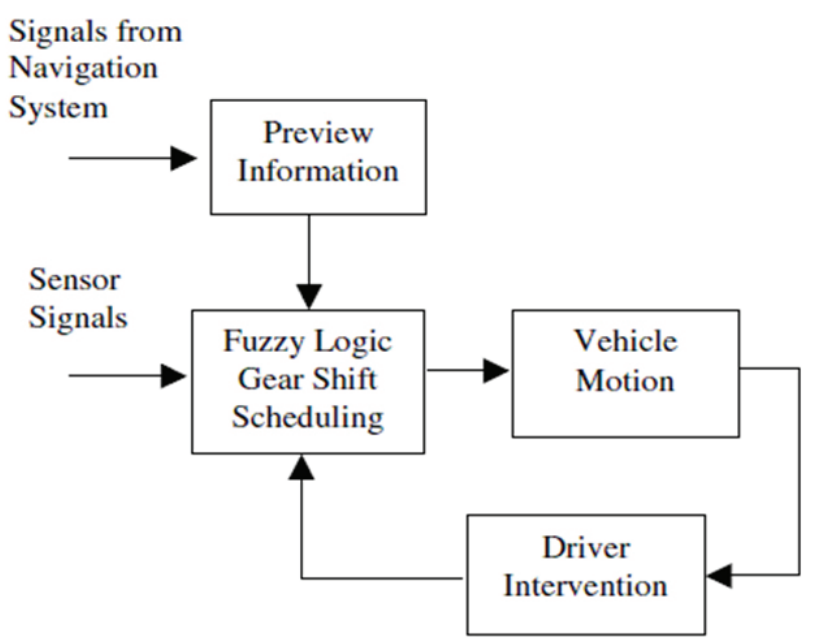

Figure 13: Block Diagram of the Gear Shift Algorithm with adaptive control [10]

The inputs of the controller are signals from sensors and GPS system and according to them controller determinants appropriate gear ratio, but it also has a feedback from driver intervention, to update the membership functions in the real time so it can accommodate better different driving patterns in the future. The advantages of this control will be shown by comparing it with the simplest (traditional) control, which takes into account just vehicle speed, throttle valve angle and accelerator pedal position as input parameters. Problems in traditional control are expressed especially during driving on the road slope. During uphill driving, the driver releases the gas pedal before entering the curve to reduce vehicle speed and in traditional observation of just a vehicle speed and throttle valve angle, upshift could be done. But right after the curve, driver presses the accelerator pedal to increase speed, when the downshift must occur. During downhill driving, because of decreasing throttle valve angle, the control unit will upshift what directly reduces the engine brake effect. Desired flexible shift control, besides basic input parameters, also observes factors such as, road grade, steering angle, vehicle acceleration and vehicle mass, toward to achieve better performance, fuel and emission characteristics, so unnecessary gear shifting could be avoided.

\section{CONCLUSION}

Automatic transmissions for vehicles with internal combustion engines could be broadly divided, according to their principle of operation, into four described concepts (AMT, HMT, CVT and DCT). All four concepts are widely used today, but in different share according to the market demands. The most used are of course HMTs because of the long history of usage and development. People in Europe generally more prefer manual transmission, so even development of automatic transmission was determined by automatization of that well known operating principle. Thus was created AMT system. Also, robotization of the manual transmission designed DCT, characterized by high efficiency, high bearing forces, no interruption of the tractive force and fast gear shifting. As already mentioned, in Japan and USA there are much more vehicles with automatic transmissions than in Europe. Especially in Japan, the most popular solution is CVT because of its features such as, optimal fuel consumption in entire engine map, high ratio span, high comfort and improved driveability. There is a growing interest of usage of CVT concept all around the world, but it refers only for lower vehicle segments, caused by power transfer limitations, related to the slipping of the friction element. Its greater application is also related to common use of CVT concept on hybrid vehicles. Hybrid transmissions are specific subset of automatic transmissions. Depending on the concept of hybrid systems different constructions of hybrid transmissions are in use. In many hybrid vehicles is used a constantly variable drive ratio, without relying on belts and pulleys. This can be accomplished by proper regulation of electric motors, whose output characteristics are the most similar to the desired ideal traction hyperbola over other types of powertrain. It should be mentioned that simpler hybrid vehicles use a conventional CVT, or even conventional manual or hydrodynamic mechanical transmission. 
But hybrid transmissions also include devices for power splitting between power sources, and their proper regulation, by hybrid control system is crucial for obtaining desired output performance in accordance with fuel economy and battery state of charge. Regardless of the type of automatic transmission and the type of power source it is obvious that in future control strategies of ATs will be more and more complicated. The issue of gear shifting optimization still represents a real challenge to scientists and experts in the field of motor vehicles, because only optimized gear shifting enables the best possible relation between vehicle motion regimes and engine working regimes $[03,02]$. Toward a contribution to gear shift optimization many parameters will be observed with implementation of adaptive functions which will compare actual (measured) and set (calculated) value of some signals in order to obtain functionality of the system in defined limits. It will be very apparent further integration of electronic transmission control system into one global system which will also include GPS navigation, capable to predict appropriate gear ratio according to operating state of the vehicle and road conditions, taking into account desired vehicle performance, fuel economy, exhaust emission, traffic safety, comfort and convenience, in order to obtain maximal efficiency. For accomplishing such a complicated goal application of fuzzy logic is very perspective, especially when control algorithms are upgraded with artificial intelligence. It is quite evident that further contribution to automatic transmissions will be obtained through more mechatronics usage, networking and soft computing application. It is also well known that maintenance management has a delay in relation to technical development (Management Gap) [12]. In order to compensate this negative fact for the maintenance systems of large fleets of vehicles, probably sophisticated expert systems for problem solving will be developed. A significant influence for maintainability these complex and networked systems will have engineers in research and development departments through integration of proper safety and diagnosis functions into the control algorithms.

\section{ACKNOWLEDGEMENTS}

This paper is a result of two important projects financed by the Ministry of Education, Science and Technological Development of the Republic of Serbia (project number TR 35045 - "Sci- entifi c-Technological Support to Enhancing the Safety of Special Road and Rail Vehicles" and TR 35040 - "Developed New Methods for Diagnosis and Examination Mechanical Structures"). The authors wish to express their gratitude to all persons who helped making this paper better.

\section{REFERENCES}

1) Bauer, H. (editor) (2004) Electronic Transmission Control ETC, Stuttgart, Robert Bosch $\mathrm{GmbH}$.

2) Blagojevic, I., Ivanovic, G., Jankovic, S., Popovic, V. (2012) A model for gear shifting optimization in motor vehicles, Transactions of FAMENA, 36 (2), 51-66.

3) Blagojevic, I., Vorotovic, G., Ivanovic, G., Jankovic, S., Popovic, V. (2012) Energy efficiency improvement by gear shifting optimization, Thermal Science, 17(1), 91-105.

4) http://auto.howstuffworks.com/cvt2.htm, preuzeto 3.2.2015.

5) http://www.youtube.com/watch?v=pnuuZd9seg, preuzeto 3.2.2015.

6) Jurgen, R.,Denenberg, J. (1999) Automotive Electronics Handbook (2nd ed), New York, McGraw-Hill.

7) Naunheimer, H., Bertsche, B., Ryborz, J., Novak, W. (2011) Automotive Transmissions - Fundamentals, Selection, Design and Application (2nd ed), Berlin, Springer-Verlag

8) Poliščuk, J.E. (2004) Ekspertni sistemi, Podgorica, Faculty of Electrical Engineering.

9) Stanojevic, D., Spasojevic, V., Stevanovic, I., Nedic, A. (2013) The contemporary automatic gearboxes - Review of the current state and interpretation of advantages and disadvantages of their use with respect to vehicle performance and traffic safety, Journal of Applied Engineering Science, 11(2), 89-97.

10) Sun, Z., Habbale, K. Challenges and Opportunities in Automotive Transmission Control, In proceedings of American Control Conference, June 8-10, 2005, Portland, 3284-3289.

11) The $02 E$ Direct Shift Gearbox - Design and Function, Self Study Program, Course Number 851403 (2004), Auburn Hills, Volkswagen of America, Inc.

12) Vasic, B. (2004) Menadžment $i$ inženjering $u$ održavanju, Beograd, Institut za istrazivanja i projektovanja u privredi.

13) Yao, C.-H. (2008) Automotive Transmissions: Efficiently Transferring Power from Engine to Wheels, ProQuest Discovery Guides.

Paper sent to revision: 13.02.2015.

Paper ready for publication: 12.03.2015. 